\title{
Clinical Trials to Improve the First Insemination Conception Rate in Postpartum Holstein Cows with Urovagina
}

\author{
Gamal Absy \\ Department of Theriogenology, Faculty of Veterinary Medicine, Suez Canal \\ University, Ismailia, Egypt.
}

\begin{abstract}
This study was carried out on a total of 339 postpartum Holstein cows over a period of three and half years starting from November 2010 until April 2014. Out of these cows, 50 animals were free from urovagina and kept as control, while the remaining 289 cows were suffering from different degrees of urovagina (mild degree, $n=135$; moderate degree, $n=149$ and severe degree, $n=5$ ). At the time of first postpartum insemination, cows with urovagina were classified into untreated control group (included 45, 41and 2 cows with mild, moderate and severe urovagina, respectively) and saline flushed alone (included 45, 48 and only one animals with mild, moderate and severe urovagina, respectively) or in combination with penicillinstreptomycine (included 42, 60 and 2 cows with mild, moderate and severe urovagina, respectively). The first insemination conception rate decreased significantly $(\mathrm{p} \leq 0.01)$ in untreated cows with moderate urovagina, but not in cows with mild urovagina compared to that of normal animals without urovagina. Moreover, in cows with mild urovagina, neither saline flushing of the genital tract alone nor in combination with antibiotic improved the first postpartum insemination conception rate. On the other hand, in cows with moderate urovagina, the first insemination conception rate tended to increase $(p=0.07)$ for cows flushed with saline alone and showed a significant $(p \leq 0.05)$ increase for those animals flushed with saline mixed with antibiotic as compared with untreated control cases of moderate urovagina.
\end{abstract}

Key words: Urovagina, cattle, treatment, conception rate

\section{Introduction}

Declining reproductive performance of dairy cows has been widely reported since the mid - $1980 \mathrm{~S}$ (Lopez- Gatius, 2003). Many reproductive disorders have been arising with the trend in increasing milk production in dairy cows leading to poor reproductive performance (Nabel et al., 1993; 
Butler, 1998; Royal et al., 2000 and Lucy, 2001).

Urovagina (vesico-vaginal reflux), the accumulation of urine in the cranial portion of the vagina, is one of the most common reproductive disorders in mare (Mckinnon and Belden, 1988; Hooper and Taylor, 1995 and Sellnow, 1996) and certain breeds of dairy cows particularly Charolais and Holstein (Noakes et al, 2001 and Gautam and Nakao, 2009). The latter investigators found that $26.7 \%$ of lactations in Holstein cows had urovagina. In the cow morphological changes in anatomy of the genital tract, such as the cranio-ventral displacement of the vagina and uterus, cause cranial flow of the urine and its pooling around the cervix (Hudson, 1986; Jean et al, 1988 and Wolfe and Baird, 1993).

Urovagina is considered as an important cause of subfertility in dairy cows, compromising animal health and resulting in production and economic losses (Gilbert et al, 1989 and Gautam and Nakao, 2009). There are few studies described the impact of urovagina on reproductive performance. The only available literature on the hand (Gautam and Nakao, 2009) found a detrimental effect of urovagina on reproductive performance based on the degree of urovagina or the amount of accumulated (pooled) urine in the anterior vagina. Only moderate (urine covering less than or equal to half portion of the external cervical os ) and sever (urine covering more than half of the external cervical os) degrees of urovagina were associated with significant reduction in pregnancy rate and were defined as clinically relevant urovagina.

Available treatment options for urovagina include complex and invasive surgical interventions to correct the anatomical abnormalities and reduce or eliminate the flow back of the urine within the vagina through remodeling of the reproductive tract (Hudson, 1986; Wolf and Baird, 1993; Youngquist 1997 and Gonzalez-Martin et al, 2008). However, the mentioned surgical procedures are expensive, risky to the animal, require a prolonged recovery period and have limited success in resumption of full reproductive capabilities of the animal (Prado et al, 2007). On the other hand, practical alternatives to surgical treatment of urovagina in cows have not been previously investigated with the except of that later study of ozone flush to genital tract (Zobel et al, 2012). The ozone or streptomycin mixed in saline flushes coupled with intra-cornual insemination presented an effective treatment option for urovagina and led to successful conceptions and pregnancies in dairy cows.

The objective of this study was to investigate the effect of urovagina in postpartum Holstein cows on the first insemination conception rate. Another objective of the study was directed to temporarily alleviate the 
possible effects of urine in early diagnosed cases of urovagina on the micro-environment of the genital tract (at the first postpartum insemination time) as a trial to improve the conception rate. So, the effect of flushing the genital tract at the time of first postpartum insemination with saline alone or in combination with penicillinstreptomycin on the conception rate in cows with urovagina was also studied.

\section{Materials and methods Animals:}

This study was carried out on a total of 339 postpartum Holstein Friesian cows belonged to four dairy farms (two farms at Sharkia province and the other two farms near the desert road between Cairo and Ismailia). The study was extended over the period of three years and half starting from beginning of November 2010 until the end of April, 2014.

The parity of the cows was ranged from one to four. All cows in the four farms (including the studied ones) were kept on free yards with an average of 50 cows per pen. Management practices and feeding regimens were nearly similar in all the farms.

The cows were fed concentrate (from corn meal, soyabean, wheat bran and minerals) according to the amount of milk production and based on the normal requirements recommended by NRC (1989). Corn silage was added to the ration.
The cows fed hay and drank water ad libitum. All cows were milked three times daily. All studied cows were apparently healthy and free from ectoparasites.

\section{Examination protocol:}

Clinical gynecological examination were done for all calved cows between 30 and 50 days postpartum. This examination included vaginal examination followed by transrectal palpation of the genital tract. For vaginal examination, the vulva was washed several times, dried and wiped with a piece of cotton soaked in $70 \%$ alcohol. Sanitised metal vaginal specula were used for vaginal exploration with the help of a torch light. The contents of the vagina or the external cervical orifice (if any were present) were aspirated with a 50-ml syringe fitted to an AI gun sheath and transferred into a glass test tube. The recovered fluid was checked for color (clear or yellowish), transparency, consistency(watery or mucoid) and smell (uremic or no smell). During vaginoscopy, congestion, protrusion and degree of opening of the external cervical os were also recorded.

Transrectal palpation of the genital tract was performed to determine the diameter, location, consistency, symmetry of uterine horns, fluid presence in the uterus, size of the ovaries and the presence of any palpable ovarian structures.

Cows diagnosed with clinical endometritis as well as those having 
purulent exudate in the vaginal contents were treated and excluded from the study because of the possible effect on the result.

Estrus was checked by trained attendants continuously through the day and night. All studied animals were inseminated artificially by the investigator after a waiting period of 45 days postpartum. Estrus was induced in all cows that did not come in heat spontaneously (this represented the majority of cows) by intramuscular injection of hormone regimen. This hormone regimen included the ordinary ovisynch program or PGF2 $\alpha$ analogues (depending on the present ovarian structures).

Estrus was confirmed by the presence of a dominant follicle on one ovary, tonic or erected uterus and vaginoscopic finding of mucous and/or open cervix. This confirmation was done immediately before insemination of the cows in the proper time (8-14 hours from onset of standing heat in cows observed in estrus or in the due time for those cows induced by hormone).

Frozen semen originated from one bull (Holstein-Friesian breed, ABS Global Inc., USA) was thawed in water at temperature from 36 to $37^{\circ}$ $\mathrm{c}$ and used to inseminate the cows to minimize the influence of semen on conception rate. Insemination of all the studied cows (along the whole years of study) was restricted only to the period from the beginning of November each year to the end of April of the next year.

\section{Experimental design and treatment:}

At the time of insemination, the studied cows were grouped as following: control normal cows included 50 cows that were free from urovagina, these cows were inseminated as usual without receiving any treatment and were served as a control group to compare their results with those untreated cows with urovagina. Cows with urovagina included 289 cows that had excess vaginal contents (fluid) characterized by at least two of the following indicators: watery, yellow in colour and uremic odour (odour of ammonia). These Cows with urovagina were further classified according to the extent of the fluid covering of the external cervical orifice as previously described by Gautam and Nakao (2009) into: A-Mild urovagina $(n=135)$ : small amount of urine or urine mixed mucous only on the floor of the vagina but not covering the external cervical os.

B-Moderate urovagina $(n=149)$ : the fluid covering up to half of the external cervical os and with some risk of urine entering into the uterus.

C-Severe urovagina $(n=5)$ : large amounts of fluid covering more than half or the entire external cervical os, with a high risk of urine entering the uterus. 
The treatment was restricted only to a great portion of urovagina cases and it was applied at time of first postpartum insemination. The goal of the treatment was directed to achieve pregnancy, not to cure urovagina. Care was done (with respect to the month of insemination or parity of the cows) to avoid any seasonal or parity effect on treatment. The initial approach before treatment always included removal of the existing fluid from the vagina through the vaginal speculum, facilitated by transrectal massage of the uterus and vagina. Based on the applied treatment protocol, all studied cows with urovagina were classified into: A- Control untreated urovagina: Included 48 cows with mild urovagina, 41 cows with moderate urovagina and 2 cows with severe urovagina. These cows were inseminated by recto-vaginal technique after removal of the existing fluid from the vagina by 5 minutes and without any applied treatment. The AI gun (with disposable plastic cover over its covering sheath) was initially inserted pointing upwards at angle of about $30^{\circ}$ to avoid entering the urethral meatus or fossa and then moved horizontally until it reaches the external os of the cervix. At this site the plastic cover is slipped back over the covering sheath of AI gun just before introducing of the catheter into the cervical canal. The semen was deposited gradually into the short uterine body just cranial to the internal os of the cervix (Noakes et al, 2001).

B- Treated urovagina: Included urovagina cases that were treated at the time of insemination after removal of the existing vaginal fluid. The treated cows with urovagina were assigned into two groups:

1. Saline flushed cows: Included 94 cows (45 with mild urovagina, 48 with moderate urovagina and only one with severe urovagina) that were flushed immediately after removal of the existing vaginal fluid using only sterile physiological saline. The genital tract was rinsed with $250 \mathrm{ml}$ of $0.9 \% \mathrm{Nacl}$ solution that was infused into the uterine body and vagina via a $100 \mathrm{ml}$ syringe fitted to an AI gun sheath $(50 \mathrm{ml}$ into the uterine body and $200 \mathrm{ml}$ into the vagina). Five minutes later, the flushed saline was evacuated by transrectal massage of the uterus and vagina. Artificial insemination was done 5 minutes later in a similar manner to that described for control groups.

2. Saline with antibiotic flushed cows: Included 104 cows (42 with mild, 60 with moderate and 2 with severe urovagina) that were flushed also after removal of the existing vaginal fluid using sterile saline mixed with sterile antibiotic. The used antibiotic for each cow was $3200000 \mathrm{IU}$ penicillin and $4 \mathrm{gm}$ of streptomycine (2 vials of stropenJect, Egyptian Co. for chemicals and pharmaceuticals, Adwia, Egypt).The sterile solution of 
antibiotic in saline was used to irrigate and rinse the uterus and vagina followed by evacuation of the flush and artificial insemination as described previously.

All inseminated cows were diagnosed for pregnancy starting from day 28 after insemination using a real time B-mode ultrasound scanner SonoScape A5v (SonoScape, China) equipped with 7.0 MHz transrectal transducer.

\section{Statistical analysis:}

The number and percentage of cows that conceived to first insemination were calculated in all studied cows. The data of the five cows with severe urovagina were included with that of moderate urovagina because of the limited number of cases in this group and the similarity between the two groups on the risk of entering of urine into the uterus. To study the effect of urovagina on the first insemination conception rate, the percentage of cows conceived to first insemination in normal cows without urovagina was compared with that of untreated cows with mild or moderate urovagina using Chi-Square analysis adopted in the GraphPad prism ${ }^{\circledR}$ version 5.01 (GraphPad software, San Diego, USA).

The percentage of untreated cows with mild or moderate urovagina that conceived to first postpartum insemination were compared to those with mild or moderate urovagina flushed with saline alone or in combination with antibiotic using also Chi-Square analysis.

\section{Results and discussion}

The effect of urovagina in postpartum Holstein cows on the first insemination conception rate As shown in table (1), it was found that out of a total of 50 normal cows without urovagina, 24 animals $(48 \%)$ conceived from the first insemination. On the other hand, Out of a total of 48 untreated cows with mild urovagina, 22 cows $(45.83 \%)$ conceived from the first insemination. There was no significant difference regarding the first insemination conception rate between normal cows without urovagina and those untreated cows with mild degree of urovagina. These results are in consistent with those reported by Gautam and Nakao (2009) who found that mild degree of urovagina was not associated with reduced pregnancy rate. These results may be explained by the fact that mild cases of urovagina have no risk of urine to enter into the uterus, thus no detrimental effect on fertility could be observed in this group.

Out of 43 untreated cows with moderate urovagina, only 9 animals $(20.93 \%)$ conceived to the first postpartum insemination compared to a percentage of $48 \%$ of normal cows (without a urovagina) that conceived from the first insemination. The first insemination 
conception rate decreased significantly $(\mathrm{P} \leq 0.01)$ in untreated cows with moderate urovagina as compared with that of normal cows without urovagina. These results are similar to those of Gautam and Nakao (2009) who found that moderate and severe degrees of urovagina (defined as clinically relevant urovagina) were associated with significant reduction in pregnancy rate and other parameters of reproductive performance. Along the same line, Gonzales-Martin et al (2008) reported urovagina as an important cause of infertility in cows. However, these results might be expected because cases of moderate urovagina have high risk of urine entering into the cervix and uterus thereby causing infertility due to spermicidal action of urine and possible chronic endometritis (Hudson, 1986; Easley, 1988 and Gilbert et al, 1989). Also, in mares with urovagina, Monin (1972) reported a lethal effect of pooled urine on spermatozoa resulting in more services per conception.

The effect of saline flush alone or in combination with antibiotic on the first insemination conception rate in postpartum cows with urovagina

As shown in table (2), it was found that in postpartum Holstein cows with mild degree of urovagina, neither saline flush of the genital tract alone nor saline flush with antibiotic (penicillin-streptomycin) resulted in improvement of the first insemination conception rate. The first insemination conception rate of cows with mild urovagina flushed with saline alone and saline mixed with antibiotic were 46.17 and $47.62 \%$ respectively, compared to a rate of $45.83 \%$ for untreated cows with mild urovagina. These results might be expected since mild degree of urovagina (with no risk of urine to enter the uterus) did not impair the conception in the current study or the other parameters of reproductive perfomance in the previous study of Gautam and Nakao (2009).

In postpartum cows with moderate urovagina, saline flushing of the genital tract just before insemination tended to improve $(\mathrm{P}=$ 0.07) the first insemination conception rate as compared with untreated control cows. Of a total of 49 cows with moderate urovagina flushed with saline alone, 19 $(38.78 \%)$ conceived to first insemination compared to only 9 cases $(20.93 \%)$ out of a total of 43 untreated cows with moderate urovagina. Also, the present study revealed a significant $(\mathrm{p}<0.05)$ effect of saline flushing with penicillin-streptomycin on increasing the first insemination conception rate in postpartum cows with moderate urovagina as compared to those untreated control cases. Of a total of 62 cows with moderate urovagina flushed with saline mixed with antibiotic, 27 $(43.55 \%)$ animals conceived to first insemination compared to only 9 $(20.93 \%)$ animals that conceived 
out of a total of 43 untreated control cows with moderate urovagina. This observed improvement in first insemination conception rate in flushed cows with moderate urovagina either with saline alone or in combination with antibiotics can be explained by an effective removal of the urine and elimination of the acidic environment and its spermicidal effect (Zobel et al, 2012). Moderate cases of urovagina present a high risk of urine entering the cervix and uterus and cause infertility because of spermicidal effect of urine and chronic irritation of the mucosa resulting in vaginitis, cervicitis and endometritis (Monin, 1972; Hudson, 1986; Gilbert et al, 1989; Wolfe and Baird, 1993; Youngquist, 1997 and Easley, 1998). The present study excluded all cases of clinical genital tract infection. Also, no attempt was done to determine the association between urovagina cases in this study and the possible subclinical endometritis.

However, the observed significant improvement in conception rate of postpartum cows with moderate urovagina that flushed with saline mixed with antibiotic might also be attributed to the reduction of the possible non-diagnosed cases of urovagina-associated subclinical endometritis after flushing. The reduction in cases of urovaginaassociated subclinical endometritis might permitted a favorable environment for a proper embryonic attachment to the uterine wall. In cattle, Noakes et al (2001) reported that $63 \%$ of infertile cows with no clinical abnormalities showed a histological evidence of endometritis and this subclinical endometritis was a major contributor to the repeat breeder syndrome. Also in human with in vitro fertilization failure, subclinical endometrial infection has a role in implantation failure, spontaneous abortion and preterm birth because of the effects of bacterial endotoxins and inflammatory mediators produced by the host, cytokines and chemokines (Romero et al, 2004).

In conclusion, the first insemination conception rate decreased significantly $\quad(\mathrm{P}<\quad 0.01) \quad$ in postpartum Holstein cows with moderate degree of urovagina, but not in those with mild degree of urovagina. Evacuation of the vaginal contents and flushing of the genital tract (just before insemination) with saline alone or in combination with antibiotic (pencillin-streptomycin) resulted in increasing the first insemination conception rate in postpartum cows with moderate degree of urovagina.

\section{Refernces}

Butler, W. R. (1998): Effect of protein nutrition on ovarian and uterine physiology in dairy cattle: A review. Journal of Dairy Science, 81(9): 2533-2539.

Gautam, G., and Nakao, T. (2009): Prevalence of urovagina 
and its effects on reproductive performance in Holstein cows. Theriogenology, 71(9): 1451-1461.

Gilbert, R. O., Wilson, D. G., Levine, S. A., and Bosu, W. T. (1989): Surgical management of urovagina and associated infertility in a cow. Journal of the American Veterinary

Association, 194(7): 931-932.

González-Martín, J. V., Astiz, S., Elvira, L., and López-Gatius, F. (2008): New surgical technique to correct urovagina improves the fertility of dairy cows. Theriogenology, 69(3): 360365.

Hooper, R. N., and Taylor, T. S. (1995): Urinary surgery. The Veterinary clinics of North America. Food Animal Practice, 11(1): 95-121.

Hudson, R. S. (1986): Genital surgery of the cow. Current Therapy in Theriogenology, 2: 341352.

Jean, G. S., Hull, B. L., Robertson, J. T., Hoffsis, G. F., and Haibel, G. K. (1988): Urethral Extension for Correction of Urovagina in Cattle A Review of 14 Cases. Veterinary Surgery, 17(5): 258-262.

LópezGatius F. (2003): Is fertility declining in dairy cattle? A retrospective study in northeastern Spain.Theriogenology, 60: 89-99.

Lucy, M. C. (2001): Reproductive loss in high-producing dairy cattle: where will it end? Journal of Dairy Science, 84(6): 1277-1293.
McKinnon, A. O., and Belden, J. O. (1988): A urethral extension technique to correct urine pooling (vesicovaginal reflux) in mares. Journal of the American Veterinary Medical Association, 192(5): 647-650.

Monin, T. (1972): Vaginoplasty: a surgical treatment for urine pooling in the mare. In Proc $18^{\text {th }}$ Am. Assoc. Equine Pract., pp. 99-102.

Nebel, R. L., and McGilliard, $M$. L. (1993): Interactions of high milk yield and reproductive performance in dairy cows. Journal of Dairy Science, 76(10): 3257-3268.

Noakes, D. E., Parkinson, T. J., and England, G. C. (2001): Arthur's veterinary reproduction and obstetrics. Bailliere Tindall, pp. 399- 581.

NRC (1989): Nutrient Requirements of Dairy Cattle. $6^{\text {th }}$ rev. ed. Natl. Acad. Sci. Washington, DC.

Prado, T. M., Schumacher, J., Hayden, S. S., Donnell, R. L., and Rohrbach, B. W. (2007): Evaluation of a modified surgical technique to correct urine pooling in cows. Theriogenology, 67(9): 15121517.

Romero, R., Espinoza, J., and Mazor, M. (2004): Can endometrial infection/inflammation explain implantation failure, spontaneous abortion, and preterm birth after in vitro fertilization?. Fertility and Sterility, 82(4): 799-804. Royal, M. D., Darwash, A. O., Flint, A. P. F., Webb, R., 
Woolliams, J. A., and Lamming, G. E. (2000): Declining fertility in dairy cattle: changes in traditional and endocrine parameters of fertility. Animal Science, 70(3): 487-501.

Sellnow, L. (1996). Urine pooling: causes and treatment. The Horse, April issue, 52-56.

Wolfe, D. F., and Baird, A. N. (1993): Female urogenital surgery in cattle. The Veterinary Clinics of North America. Food Animal Practice, 9(2): 369-388.
Youngquist, R. S. (1997): Surgical correction of abnormalities of genital organs of cows. In: Youngquist, RS, editor. Current Therapy in Theriogenology, WB Saunders ; pp. 429-440.

Zobel, R., Tkalčić, S., Štoković, I., Pipal, I., and Buić, V. (2012): Efficacy of ozone as a novel treatment option for urovagina in dairy cows. Reproduction in Domestic Animals, 47(2): 293-298.

Table 1: The effect of urovagina in postpartum Holstein cows on the first insemination conception rate

\begin{tabular}{|c|c|c|c|c|}
\hline Animals & $\begin{array}{c}\text { Total } \\
\text { No. }\end{array}$ & $\begin{array}{c}\text { No. and } \\
\text { percentage }(\%) \\
\text { of cows } \\
\text { conceived }\end{array}$ & $\begin{array}{c}\text { No. and } \\
\text { percentage (\%) of } \\
\text { cows failed to } \\
\text { conceive }\end{array}$ & $P$ value \\
\hline $\begin{array}{c}\text { Normal cows } \\
\text { without } \\
\text { urovagina } \\
\text { (control) }\end{array}$ & 50 & $24(48)$ & $26(52)$ & $\begin{array}{c}0.84 \text { (normal } \\
\text { control vs. } \\
\text { mild } \\
\text { urovagina) }\end{array}$ \\
\hline $\begin{array}{c}\text { Mild urovagina } \\
\text { Moderate }\end{array}$ & 48 & $22(45.83)$ & $26(54.17)$ & $\begin{array}{c}0.01 \text { (normal } \\
\text { control vs. } \\
\text { moderate } \\
\text { urovagina) }\end{array}$ \\
\hline \begin{tabular}{c} 
urovagina* \\
\hline
\end{tabular} & 43 & $9(20.93)$ & $34(79.07)$ & \\
\hline
\end{tabular}

* The few cases of severe urovagina $(n=2)$ were added to the cases of moderat degree of urovagina during the statistical analysis 
Table 2: The effect of saline flushing alone or in combination with antibiotic (penicillin-streptomycin) on the first insemination conception rate in postpartum Holstein cows with urovagina

\begin{tabular}{|c|c|c|c|c|}
\hline Animals & $\begin{array}{l}\text { Total } \\
\text { No. }\end{array}$ & $\begin{array}{c}\text { No. and } \\
\text { percentage }(\%) \\
\text { of cows } \\
\text { conceived }\end{array}$ & $\begin{array}{c}\text { No. and } \\
\text { percentage }(\%) \text { of } \\
\text { cows failed to } \\
\text { conceive }\end{array}$ & $P$ value \\
\hline \multicolumn{5}{|l|}{$\begin{array}{c}\text { Mild } \\
\text { urovagina }\end{array}$} \\
\hline $\begin{array}{l}\text { Untreated } \\
\text { control }\end{array}$ & 48 & $22(45.83)$ & $26(54.17)$ & \\
\hline Saline flush & 45 & $21(46.67)$ & $24(53.33)$ & $\begin{array}{l}1.0 \text { (untreated } \\
\text { control vs. saline } \\
\text { flush) }\end{array}$ \\
\hline $\begin{array}{l}\text { Saline with } \\
\text { antibiotic } \\
\text { flush }\end{array}$ & 42 & $20(47.62)$ & $22(52.38)$ & $\begin{array}{c}1.0 \text { (untreated } \\
\text { control vs. saline } \\
\text { with antibiotic } \\
\text { flush) }\end{array}$ \\
\hline \multicolumn{5}{|l|}{$\begin{array}{l}\text { Moderate } \\
\text { urovagina* }\end{array}$} \\
\hline $\begin{array}{l}\text { Untreated } \\
\text { control }\end{array}$ & 43 & $9(20.93)$ & 34 (79.07) & \\
\hline Saline flush & 49 & $19(38.78)$ & $30(61.22)$ & $\begin{array}{l}0.07 \text { (untreated } \\
\text { control vs. saline } \\
\text { flush) }\end{array}$ \\
\hline $\begin{array}{l}\text { Saline with } \\
\text { antibiotic } \\
\text { flush }\end{array}$ & 62 & $27(43.55)$ & $35(56.45)$ & $\begin{array}{c}0.02 \text { (untreated } \\
\text { control vs. saline } \\
\text { with antibiotic } \\
\text { flush) }\end{array}$ \\
\hline
\end{tabular}

* The few cases of severe urovagina $(n=5)$ were added to the cases of moderat degree of urovagina each in the crosponding group during the statistical analysis 


\section{محاولات اكلينيكية لتحسين نسبة الاخصاب للتلقيح الاول بعد الولادة في الابقار الهولشتين ذات تر اكم البول بالمهيل}

\section{جمال عبسي محم}

قسم التوليب والتناسل والتلقبح الاصطناعي ـ كلبة الطب البيطري - جامعة قناة السويس

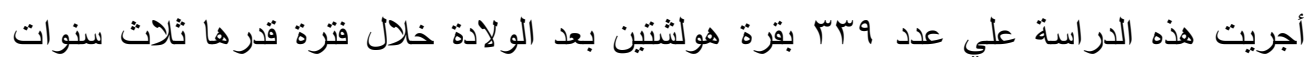

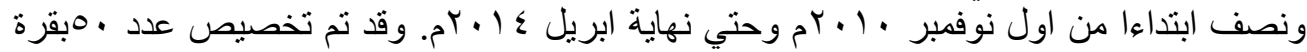

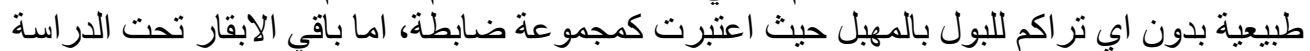

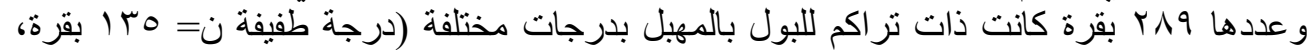

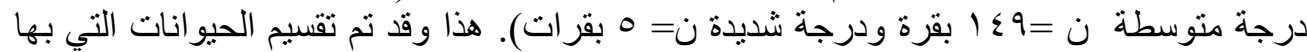

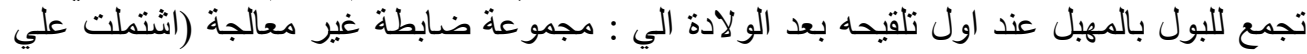

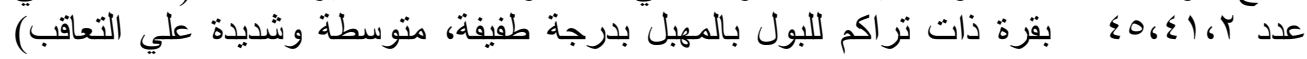

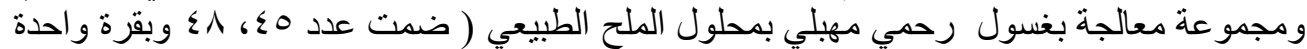

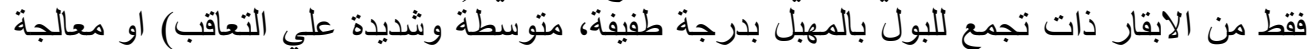

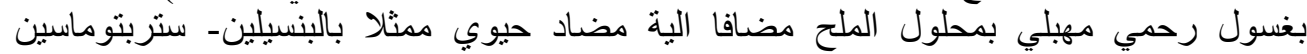

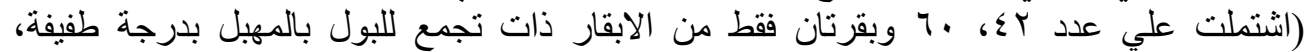

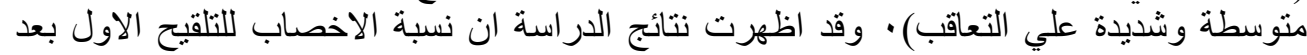

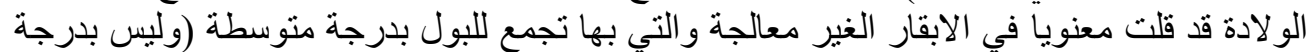

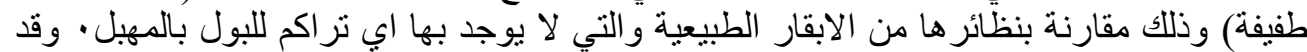

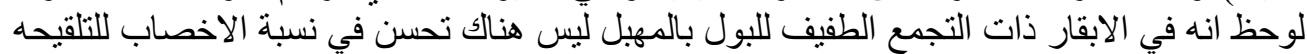

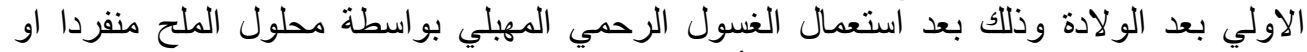

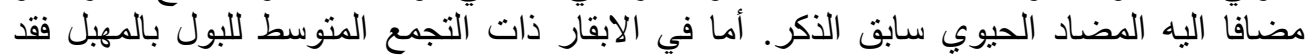

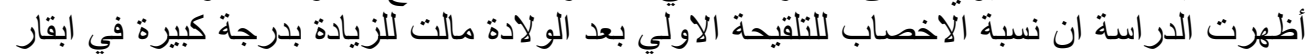

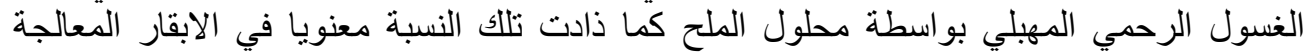

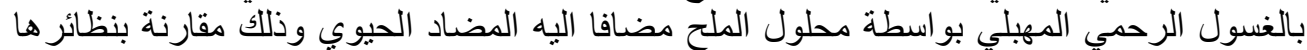
من الحيو انات بالمجمو عة الضابطة والغير معالجة و التي بها تجمع متو سط للبول بالمهيل. 